\title{
Bioactives Profile of Purple and Black Tomato: Potential Applications in the Pharmaceutical Field Purple and Black Tomato
}

\begin{abstract}
SIMONE PERNA ${ }^{1}$, SHERRY NASRALLA TAWFIK ${ }^{2}$, T.ARIQ A. ALALWAN ${ }^{1}$, CLARA GASPARRI $^{3}$, GABRIELLA PERONI ${ }^{*}$, ZAHRAA ALAALI ${ }^{1}$, HIND MUBARAK ${ }^{1}$, EBTISAM BIN BUTTI ${ }^{1}$, MONAA. AZIZ ALJAR ${ }^{4}$, VITTORIA INFANTINO ${ }^{3}$, MARIANGELA RONDANELLI $\left.\right|^{5,6}$

${ }^{1}$ Department of Biology, College of Science, University of Bahrain, Sakhir Campus P. O. Box 32038 Kingdom of Bahrain,2Pharmacy Program, Pharmacology Stream, Allied Health Department, College of Health and Sport Sciences, University of Bahrain, Manama P.O. Box 32038, Kingdom of Bahrain, ${ }^{3}$ Endocrinology and Nutrition Unit, Azienda di Servizi alla Persona Istituto Santa Margherita, University of Pavia, Pavia, 27100 Italy, ${ }^{4}$ Department of Chemistry, College of Science, University of Bahrain, Sakhir Campus P. O. Box 32038 Kingdom of Bahrain, ${ }^{5}$ Department of Public Health, Experimental and Forensic Medicine, University of Pavia, Pavia, 27100 Italy, ${ }^{6}$ IRCCS Mondino Foundation, Pavia, Italy
\end{abstract}

\section{Perna et al.: Bioactives Profile of Purple and Black Tomato}

\begin{abstract}
The purple and black tomato are sources of different antioxidants such as carotenoids and flavonoids that seem to have dose-dependent antioxidant, anti-inflammatory, anti-proliferative and hypnotic effects. The aim of this review is to discuss their advantageous role in health promotion and prophylaxis against chronic conditions induced by inflammation and oxidative stress. Data research was conducted on five major databases using specific keywords to extract relevant articles. The anti-proliferative effect was seen in a deep purple tomato in two human cancer cell lines: human colorectal adenocarcinoma cell line and HeLa cell line. Potential anticancer properties were attributed to radical scavenging activity, enzyme detoxification, reduced cell proliferation, angiogenesis and invasiveness. Ingestion of purple and black tomato seeds was proven to increase circulating melatonin levels and improve hypnosis. Purple and black tomato anthocyanin treatment was also significantly associated with increased sperm motility and spermatogenic cell density. The high content of bioactives in purple and black tomato may find application in prevention of cancer and cardiovascular diseases as well as management of sleep and fertility disorders.
\end{abstract}

Key words: Black tomato, purple tomato, anthocyanin, antioxidant, cancer, fertility

Domesticated tomato (Solanum lycopersicum L.) is one of the most valuable fruits in human nutrition, ranking seventh in worldwide production, with a global consumption estimated at 33.20 million metric tons ${ }^{[1,2]}$. Unlike other plant-derived products, tomatoes are harmless and appetizing for human consumption in their fresh ripe forms or when minimally treated ${ }^{[3]}$. Thus, the tomato fruit has evolved to be both flavorful and nutritious to frugivores ${ }^{[4]}$. Due to its remarkable nutritive value, it is recognized as a protective food that provides health-promoting antioxidants such as lycopene, $\beta$-carotene, vitamin $\mathrm{C}$, hydroxycinnamic acid derivatives and flavonoids, particularly flavonols and flavones, which are known to combat inflammation and cancer ${ }^{[1,5]}$. A variety of tomatoes exist in a range of colors, including red, orange, yellow, green, pink, white, brown, black and

*Address for correspondence

E-mail: gabriella.peroni01universitadipavia.it purple; color being an important characteristic in attracting consumers ${ }^{[5]}$.

Accumulation of anthocyanins in some wild tomato species gives rise to black and purple tomatoes, namely; Solanum chilense, S. hirsutum, $S$. cheesmanii, and $S$. lycopersicoides ${ }^{[5]}$. This feature has been carried into the domesticated tomato through interspecific $\operatorname{crosses}^{[6]}$. Domesticated tomatoes produce anthocyanin in vegetative tissues but not in the peels or pulp of the fruit ${ }^{[5]}$. Purple tomatoes contain higher levels of anthocyanin than red tomatoes,

\footnotetext{
This is an open access article distributed under the terms of the Creative Commons Attribution-NonCommercial-ShareAlike 3.0 License, which allows others to remix, tweak, and build upon the work non-commercially, as long as the author is credited and the new creations are licensed under the identical terms
}

Accepted 20 December 2020

Revised 04 September 2020

Received 13 March 2020

Indian J Pharm Sci 2020;82(6):928-935 
as well as other healthy phytochemicals, which might contribute to higher health-promoting and prophylactic activities in conditions such as diabetes, chronic degenerative diseases, cardiovascular diseases and certain types of cancers ${ }^{[6]}$. A genetically modified (GM) purple tomato was found to have a positive impact by prolonging the life of cancer-susceptible mice. Moreover, non-GM purple tomato (breeding line V118) had stronger antioxidant activities than some commercial red tomatoes ${ }^{[7]}$.

The aim of this review is to discuss the recent studies on the nutrient content of purple tomatoes and consequently their advantageous role in health promotion and prevention of chronic diseases.

\section{BIOACTIVE COMPOUNDS AND HUMAN HEALTH: ANTHOCYANINS AND CAROTENOIDS}

A polyphenol-rich diet may ameliorate undesirable clinical outcomes, by exerting pleiotropic effect on cardiometabolic risk factors by virtue of the specific action of different polyphenol subclasses: phenolic acids, anthocyanidins, flavones, flavan-3-ols, flavonols and flavanones ${ }^{[8]}$. Among these, anthocyanins (water-soluble plant pigments responsible for red, purple and blue coloration of many fruits, flowers, and leaves) have garnered recent interest from researchers because of their potential preventative and/or therapeutic effects on human health ${ }^{[9]}$. There are 702 different anthocyanins and 27 anthocyanidins (the sugar-free, aglycone forms of anthocyanins) identified in nature. However, only six anthocyanidins, namely, cyanidin, delphinidin, pelargonidin, peonidin, malvidin, and petunidin are widely distributed in the human diet, accounting for more than $90 \%$ of all known anthocyanins ${ }^{[10]}$. Chronic consumption of anthocyanins and/or anthocyanin-rich foods has been postulated to exert an array of health benefits, including but not limited to cardiovascular protection, neuroprotection, vision improvement, antidiabetic and anti-obesity properties, antiinflammatory effects, chemoprevention and cancer protection $^{[11]}$. Anthocyanin supplementation exerts beneficial metabolic effects in subjects with type 2 diabetes by improving dyslipidemia, enhancing antioxidant capacity, and preventing insulin resistance. These results were drawn from a $24 \mathrm{w}$ randomized, controlled trial on 58 diabetic patients who received $160 \mathrm{mg}$ of anthocyanins twice daily ${ }^{[12]}$. The triglyceride (TG) lowering effect observed in anthocyanin-treated subjects resulted primarily from reductions in serum apo B- and apo C-III-containing TG-rich particles due to anthocyanin intervention, demonstrating reduction in potential pro-atherogenic remnant particles, a prominent component of diabetic dyslipidemia ${ }^{[12]}$.

Another randomized pilot study, on 74 subjects with non-alcoholic fatty liver disease (NAFLD), who received $320 \mathrm{mg} / \mathrm{d}$ of bilberry and blackcurrant derived anthocyanins for $12 \mathrm{w}$, suggested that purified anthocyanin supplements may have favorable effects on insulin resistance and several plasma biomarkers of liver injury in those patients. A positive correlation between changes in plasma alanine transaminase (ALT) activities and the levels of Cytokeratin-18 M30 fragment (CK-18 M30) in anthocyanin-treated patients was also observed. These results suggest that anthocyanin supplementation reduced plasma myeloperoxidase (MPO) and showed a trend toward improvement in NAFLD fibrosis score. MPO may be a factor that directly links the hepato-protective effects of anthocyanin to its well documented anti-inflammatory and antioxidant properties ${ }^{[13]}$.

A recent study showed that daily consumption of $200 \mathrm{ml} / \mathrm{d}$ of anthocyanin-rich cherry juice for $12 \mathrm{~W}$ improved cognitive performance (verbal fluency, short-term and long-term memory) in older adults with mild-to-moderate dementia ${ }^{[14]}$. The study hypothesized that flavonoids may be more likely to hinder cognitive impairment through their actions on the brain's cellular and molecular architecture, rather than through halting disease progression ${ }^{[14]}$. The bioactive components provided by cherry juice may provide benefits, such as stimulating an up-regulation of signaling cascades in areas of the brain related to memory ${ }^{[15]}$. On the other hand, results weren't as prominent in Alzheimer's patients as the disease is associated with progressive and chronic inflammation ${ }^{[16]}$ and such pathology may mask any potential anti-inflammatory effects provided by the cherry juice.

A memory-enhancing effect was also demonstrated with daily supplementation of carotenoids; lutein, zeaxanthin, and meso-zeaxanthin in healthy subjects. Given that concentrations of these carotenoids relate positively to cognitive function, it is reasonable to hypothesize that these compounds assist in optimizing the neurocognitive environment ${ }^{[17]}$. Lutein can facilitate the transfer of compounds from one cell to another via gap junctions. Gap junction channels contribute to sharpened neuronal activity, which 
have been proposed to underlie cognitive processes such as memory, perception, and learning. Other mechanisms whereby lutein and zeaxanthin may play a neuroprotective and/or neurosupportive role have been proposed, and it has been suggested that they can enhance the structural integrity of membranes and positively impact neural efficiency ${ }^{[17]}$.

A study carried out on children demonstrated the beneficial role of mixed-carotenoid supplementation in obesity. A decrease in body mass index (BMI), z-score, waist-to-height ratio, and subcutaneous adipose tissue, was associated with the increase in the concentration of $\beta$-carotene and highmolecular-weight adiponectin by mixed-carotenoid supplementation ${ }^{[18]}$.

The health benefits of carotenoid administration on eye related-diseases, several types of cancers, cardiovascular and photosensitive disorders, have also been confirmed by recent reviews ${ }^{[19,20]}$. Carotenoids have antioxidant and anti-inflammatory activity that may protect against cardiovascular risk factors such as markers of inflammation, hyperlipidemia, hypertension, insulin resistance, and obesity. Consequent improvements in baseline blood pressure levels, reduction of inflammation, and correction of dyslipidemias can lead to an improvement of cardiovascular health ${ }^{[21]}$.

\section{MATERIALS AND METHODS}

A data research was carried out in different databases namely: PubMed (Public Medlinerun by the National Center of Biotechnology Information (NCBI) of the National Library of Medicine of Bathesda (USA)\}, Saudi Digital Library (SDL), Google scholar, Scopus, Web of Science, using the following key words: Tomato, Purple tomato, Blue tomato, Indigo rose. There were no set time limits due to the few studies conducted on this topic.

\section{RESULTS AND DISCUSSION:}

\section{Pigment contents and antioxidant activities:}

The antioxidant activity of purple tomato is due to its high content of anthocyanin, carotenoids, and phenolic compounds. Table 1 describes pigment contents of different colorful fruits and vegetables. It was found that the contents of anthocyanin in the whole fruit, peel, and flesh of the Del/Ros- transgenic tomato were $5.2 \pm 0.5,5.1 \pm 0.5$, and $5.8 \pm 0.3 \mathrm{~g} / \mathrm{kg}$ dry matter, respectively ${ }^{[22]}$. Anthocyanin content in other
TABLE 1: ADVANTAGES OF SOLID LIPID NANOPARTICLES

Advantages of solid lipid nanoparticles

Control and/or target drug release. Improve stability of pharmaceuticals.

High and enhanced drug content (compared to other carriers). Feasibilities of carrying both lipophilic and hydrophilic drugs.

Most lipids being biodegradable, SLNs have excellent biocompatibility.

Water based technology (avoid organic solvents). Easy

to scale-up and sterilize.

More affordable (less expensive than polymeric/

surfactant based carriers).

Easier to validate and gain regulatory approval.

studies was around $23 \mathrm{mg} / 100 \mathrm{~g}$ fresh weight in Jinling Moyu purple tomato ${ }^{[6]}$, and $72.31 \mathrm{mg} / 100 \mathrm{~g}$ in V118 purple tomato ${ }^{[23]}$. The purple tomato fruit peels had enhanced anthocyanin pigment accumulation, which was over 10-fold compared to any other tomato fruits evaluated in a study done by Kang et al. ${ }^{[5]}$. Compared to other types of colored tomato, purple tomato was found to have the second highest amount of anthocyanin after red tomato ${ }^{[24]}$. Comparing tomato fruits of giant purple, giant yellow, and New Zealand purple cultivators, the highest antioxidant activity and the highest anthocyanins contents were found in New Zealand purple cultivators ${ }^{[25,26]}$.Several purple vegetables have been previously studied by Li H. et al., concluding that these vegetables had high contents of anthocyanins. Although the study did not include purple tomatoes, nevertheless, the results indicated that purple vegetables generally have a high content of anthocyanins ${ }^{[27]}$.

Mladenovic et al. compared the phenolic compounds content in the extract of Russian Black Prince variety with that of hybrid Sidra first-generation selections. Results revealed that the total phenolic content (TPC) was higher in the former variety ${ }^{[28]}$. Japanese blue tomato peel extract contains a large amount of anthocyanins whereas the seed and pulp extracts contain either none or a small amount of the same pigment ${ }^{[29]}$. A recent study evaluated different pigmented rich plant materials, two fruits and two vegetables, and found that anthocyanin contents ranged from 4.9 to $38.5 \mathrm{mg} / \mathrm{g}$ dry weight (DW) ${ }^{[30]}$.

Varying amounts of carotenoids and phenolic compounds with antioxidant activity were reported on analysis of different strains of the purple tomato. The total carotenoid content of V118 was 
$234.78 \mu \mathrm{g} / \mathrm{gDW}$, while the total phenolic content was $659.11 \mathrm{mg}$ Gallic Acid Equivalent (GAE)/100 g $\mathrm{DW}^{[23]}$. In a study that aimed to determine the levels of phenolics including flavonoids in purple tomatoes, Mladenovic et al. ${ }^{[28]}$ concluded that these fruits contain high amounts of bioactive compounds. The antioxidant activities of the lipophilic extract of purple tomatoes was measured by photochemiluminescence (PCL) and Oxygen Radical Absorption Capacity (ORAC-L) assays, and the results were $30.11 \mu \mathrm{mol}$ total extract (TE)/g DW and $11.97 \mu \mathrm{mol} \mathrm{TE} / \mathrm{g} \mathrm{DW}$ respectively ${ }^{[23]}$. Antioxidant activities of purple tomatoes are either direct or indirect effects. The direct anti-oxidant activities are denoted by decreased malondialdehyde (MDA) and nitric oxide (NO) production and the indirect activities are denoted by increased glutathione peroxidase (GPx) and superoxide dismutase (SOD) activities in edematous tissue. This supports the conclusion that tomatoes containing anthocyanins can potentially provide better protection against oxidative stress related chronic diseases of humans ${ }^{[7]}$. Table 2 describes the antioxidant activity of purple tomatoes and other colorful plant materials, as a result of their bioactive components, such as carotenoids or anthocyanin (Table 3).

\section{Susceptibility to infections:}

The effect of spraying the fungal pathogen, Botrytis cinerea spore suspension was measured in both wounded and non-wounded fruits. For non-wounded

\begin{tabular}{|c|c|c|}
\hline Name of the ingredients & conc & Reference \\
\hline Lipid & $3.33 \% \mathrm{w} / \mathrm{v}$ & 17 \\
\hline Phospholipids & $0.6-1.5 \%$ & 18 \\
\hline Glycerol & $2-4 \%$ & -- \\
\hline Poloxamer 188 & $1.2-5 \% \mathrm{w} / \mathrm{w}$ & 19 \\
\hline Soy phosphatidyl choline & $95 \%$ & -- \\
\hline Compritol & $10 \%$ & -- \\
\hline Cetyl palmitate & $10 \% w / w$ & 20 \\
\hline Tego care 450 (surfactant) & $1.2 \% \mathrm{w} / \mathrm{w}$ & -- \\
\hline PEG 2000 & $0.25 \%$ & -- \\
\hline PEG 4500 & $0.5 \%$ & -- \\
\hline Tween 85 & $0.5 \%$ & 21 \\
\hline Ethyl oleate & $30 \%$ & -- \\
\hline $\mathrm{Na}$ alginate & $70 \%$ & -- \\
\hline Ethanol/butanol & $2 \%$ & 22 \\
\hline Tristearin glyceride & $95 \%$ & 18 \\
\hline PEG 400 & $5 \%$ & -- \\
\hline Isopropyl myristate & $3.60 \%$ & -- \\
\hline Pluronic F 68 & $40 \%$ & -- \\
\hline Tween 80 & $50 \%$ & 21 \\
\hline
\end{tabular}

fruit, this exposure was associated with significantly milder symptoms for purple tomatoes as compared to red tomatoes. For wounded fruits, the inoculation of $B$. cinerea spore suspension was not associated with an increase in lesion size of either fruits on day 1 post inoculation (dpi), however, there was a greater spread of infection in red tomatoes on $2 \mathrm{dpi}$ as compared to purple tomatoes. The average size of the lesions on 3 dpi was significantly smaller in purple tomatoes. This clearly indicates reduced susceptibility of purple fruits to $B$. cinerea infection ${ }^{[31]}$. The reduced susceptibility to infection is thought to be due to the high content of anthocyanins as they alter the spread of the reactive oxygen species (ROS) burst generated as part of necrotrophic infection ${ }^{[31]}$.

\section{Softening and Shelf life:}

Purple tomatoes were compared to red tomatoes in terms of softening and shelf life. Red tomatoes softened in $21 \mathrm{~d}$ when stored at $18^{\circ}$, while the time to softening of $50 \%$ of purple tomatoes to the same extent was $49 \mathrm{~d}$. The red fruits completely collapsed after $5 \mathrm{w}$ of storage, whereas the purple fruits endured up to $10 \mathrm{w}$. To measure the firmness of the fruits, a texture analyzer was used. As such, the shelf life of purple tomatoes was more than double that of red tomatoes; this isdue to the expression of the transcription factors ${ }^{[31]}$. The reduction of ROS levels may be the cause of suppression of ripening in later stages, and is caused by the hydrophilic antioxidant capacity due to the high content of anthocyanins ${ }^{[31]}$. The prolonged shelf life is attributed to the lower susceptibility of purple tomatoes to infections as mentioned previously (fig. 1) ) $^{[31]}$.

\section{Anti-inflammatory and anti-proliferative effects:}

Purple tomatoes antioxidant effects seem to be dosedependent. This has been proven by a single in vivo study on rats. The study showed that purple tomatoes caused a significant inhibition (edematous inhibition: $7.48 \%$ and $13.8 \%$ ) of carrageenan-induced rat paw edema ${ }^{[7]}$. Although this was demonstrated by one study only, results were significant, which may encourage further research to explore this property. In addition, purified anthocyanin samples from four plant sources ("Sun Black" tomato, mahaleb cherry, blackcurrant and black carrot) exhibited the capability to reduce the expression of endothelial inflammatory antigens, suggesting their potential beneficial effect in cardiovascular protection. The vascular anti-inflammatory capacity of non-acylated 


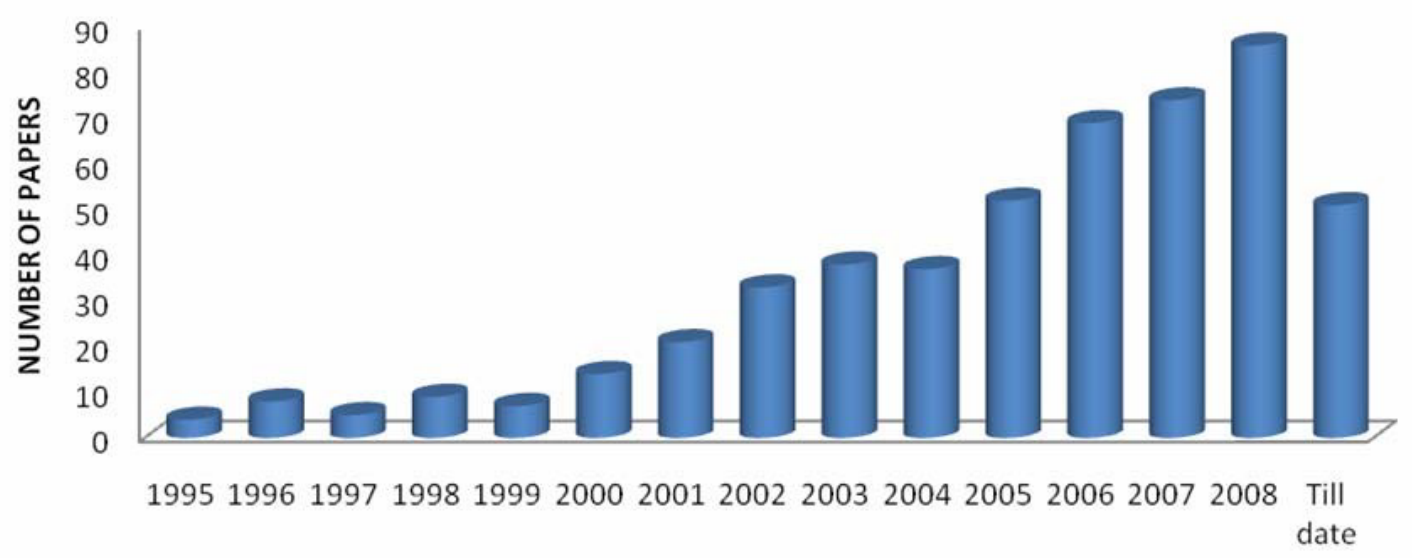

YEAR

Fig. 1: Trends in Solid lipid nanoparticles research

TABLE 3: METHOD OF SLN PREPARATION

\begin{tabular}{lc}
\hline $\begin{array}{l}\text { Different methods of SLNs } \\
\text { preparation }\end{array}$ & Reference \\
\hline High shear homogenization & $23-25$ \\
Hot homogenization Cold & 26,27 \\
homogenization & 28 \\
Ultrasonication/high speed & 29,30 \\
homogenization & 31,32 \\
Probe ultrasonication Bath & $33-37$ \\
ultrasonication & $38-40$ \\
Solvent emulsification/evaporation & 41 \\
Micro emulsion based SLN preparations & 42 \\
SLN preparation by using supercritical & \\
fluid Spray drying method & Double emulsion method \\
\hline
\end{tabular}

anthocyanins was found to be higher than that of anthocyanins acylated with cinnamic acid derivatives in accordance with their corresponding antioxidant activity $^{[30]}$.

Anti-proliferative effect was reported in a deep purple tomato fruit named Sun Black. Its skin extract was tested on two human cancer cell lines; HT-29 cell line, derived from human colorectal adenocarcinoma, and HeLa cell line, derived from human ovarian cancer. The extract had significantly inhibited cell proliferation in a dose-dependent manner ${ }^{[32]}$. In a recent pilot test, cancer-susceptible Trp53-/- mice, fed a diet supplemented with the high-content anthocyanin tomatoes, showed a significant extension of their life spans ${ }^{[33]}$.

The potential anticancer properties of anthocyanins, revealed from in vitro studies, are attributed to their radical-scavenging activity; stimulation of phase II detoxifying enzymes; reduced cell proliferation, inflammation, angiogenesis and invasiveness; and induction of apoptosis and differentiation. Anthocyanins bring about these effects through modulating the expression and activation of multiple genes associated with these cellular functions, including genes involved in the phosphatidylinositol 3-kinase/protein kinase B PI3K/Akt, extracellularsignal-regulated kinase, c-Jun N-terminal kinase, and mitogen-activated protein kinases pathways ${ }^{[34]}$.

\section{Hypnotic/Somnifacient effects:}

Recent studies quantified melatonin concentrations in black tomato, and two commercial tomato juices as well as beefsteak tomato, which was found to contain the highest level of melatonin ${ }^{[35]}$.

The latest study on this topic demonstrated that supplying beefsteak tomatoes to obese postmenopausal women with sleep problems for $8 \mathrm{w}$ raised their circulating melatonin (quantified by measuring the 6-sulphatoxymelatonin level in the morning's first-void urine), and their sleep quality was improved with extended durations of tomato consumption. Black tomato seeds prove the hypothesis that ingestion of melatonin-rich foods can increase circulating melatonin levels and improve sleep $^{[35]}$.

Previous studies have reported a wide range of melatonin levels in tomatoes, ranging from 0.03 to $23.87 \mathrm{ng} / \mathrm{g}$. This may be due to the varied growth conditions, however, further studies are necessary for addressing this issue ${ }^{[36]}$.

\section{Effects on testosterone, sperm and prostate parameters:}

It has been proposed that the lycopene found in tomatoes (Solanum lycopersicum L.) may be beneficial for prostate health due to its antioxidant properties. A 30 study meta-analysis by Rowles 
et al. in 2018, showed an inverse association between prostate cancer risk and the consumption of tomatoes among 24222 cases reported from 260461 participants; when cooked or used as a sauce $^{[37]}$. Moreover, a recent finding demonstrated that anthocyanin treatment significantly increased testes weight, sperm motility and spermatogenic cell density as well as significantly decreased apoptotic body count and 8-hydroxy-2'-deoxyguanosine(8$\mathrm{OHdG}$ ) concentrations ${ }^{[38]}$. The high content of anthocyanins in purple tomatoes makes it very suitable for transgenic labeling. It was used by Juarez $\mathrm{P}$ et al., to produce neutralizing antibodies against rotavirus $^{[3]}$.

Black and purple tomatoes are found to have significant antioxidant, anti-inflammatory, antiproliferative and hypnotic effects. They also have beneficial effects on sperm count and motility. Purple tomatoes have also demonstrated slower ripening and softening than red tomatoes, as well as better resistance to infections, which contributes to their longer shelf life. These effects are generally attributed to their content of anthocyanins, carotenoids and phenolic compounds; which vary greatly between the different strains, their cultivation conditions and the parts of the fruit itself. Although the antioxidant activity has been studied sufficiently well, further research into the anti-inflammatory and anti-proliferative effects is needed. The high content of phytochemicals of these fruits contributes to their health benefits and prophylactic properties against an array of diseases caused by oxidative stress and inflammation. Previous studies by Campestrini et $a l ., 2019$, suggested that a new variety of nutrientrich purple tomato (Solanum lycopersicum L. cv Micro-Tom) displayed the best antioxidant activities which can be associated to its highest content of carotenoids, specially lutein and $\beta$-carotenes and the Purple peel CRF had antiproliferative activity against HepG2 line (liver hepatocelullar carcinoma) at non-toxic concentrations ${ }^{[39]}$.

In addition, as suggested in 2020 by Colanero et al., the genetic characterization of the Abg mutation in purple Tomato, stronger than Aft in inducing fruit pigmentation, certainly represents an interesting new step in this direction ${ }^{[40]}$.

\section{Acknowledgments:}

None. This research received no external funding. The authors declare no conflict of interest.

\section{REFERENCES}

1. Scheffel U, Rhodes BA, Natajaran TK, Wagner HN. Albumin microspheres for study of the reticuloendothelial system. J Nucl Med 1970;13:498-503.

2. Jumaa M, Muller BW. Lipid emulsions as a novel system to reduce the hemolytic activity of lytic agents: mechanism of protective effect. Eur J Pharm Sci 2000;9:285-90.

3. Cavalli R, Caputo O, Gasco MR. Solid lipospheres of doxorubicin and idarubicin. Int J Pharm 1993;89:R9-R12.

4. Gasco MR. Method for producing solid lipid microspheres having a narrow size distribution. United states patent, USS $188837 ; 1993$.

5. Muller RH, Runge SA. Solid lipid nanoparticles (SLN) for controlled drug delivery, in: S. Benita (Ed.), Submicron emulsions in drug targeting and delivery, Amsterdam: Harwood Academic Publishers;1998:219-34.

6. Jenning V, Gysler A, Schafer-Korting M, Gohla S. Vitamin A loaded solid lipid nanoparticles for topical use: occlusive properties and drug targeting to the upper skin. Eur J Pharm Biopharm 2000;49:211-8.

7. Muller RH, Radtke M, Wissing SA. Nanostructured lipid matrices for improved microencapsulation of drug. Int $\mathrm{J}$ Pharm 2002;242:121-8.

8. Radtke M, Muller RH. Comparison of structural properties of solid lipid nanoparticles (SLN) versus other lipid particles. Proc Int Symp Control Rel Bioact Mater 2000;27:309-10.

9. Uner M. Preparation, characterization and physicochemical properties of solid lipid nanoparticles (SLN) and nanostructured lipid carriers (NLC): their benefits as colloidal drug carrier systems. Pharmazie 2006;61:375-86.

10. Muller RH, Radtke M, Wissing SA. Solid lipid nanoparticles (SLN) and nanostructured lipid carriers (NLC) in cosmetic and dermatological preparations. Adv Drug Deliv Rev 2002;54:S131-55.

11. Souto EB, Wissing SA, Barbosa CM, Muller RH. Development of a controlled release formulation based on SLN and NLC for topical clotrimazole delivery. Int J Pharm 2004;278:71-7.

12. Souto EB, Muller RH. Investigation of the factors influencing the incorporation of clotrimazole in SLN and NLC prepared by hot high-pressure homogenization. J Microencapsul 2006;23:377-88.

13. Souto EB, Muller RH. SLN and NLC for topical delivery of ketoconazole. J Microencapsul 2005;22:501-10.

14. Souto EB, Muller RH. The use of SLN and NLC as topical particulate carriers for imidazole antifungal agents. Pharmazie 2006;61:431-37.

15. Morel S, Terreno E, Ugazio E, Aime S, Gasco MR. NMR relaxometric investigations of lipid nanoparticles (SLN) containing gadolinium (III) complexes. Eur J Pharm Biopharm 1998;45:157-63.

16. Olbrich C, Gebner A, Kayser O, Muller RH. Lipid-drug conjugate (LDC) nanoparticles as novel carrier system for the hydrophilic antitrypanosomal drug diminazenediaceturate. J Drug Target 2002;10:387-96.

17. Speiser P. Lipidnanopellets als Tragersystem fur Arzneimittel zur perolen Anwendung. European Patent, EP 0167825;1990.

18. Domb AJ. Lipospheres for controlled delivery of substances. United States Patent, USS 188837;1993.

19. Ahlin P, Kristl J, Kobar S. Optimization of procedure 
parameters and physical stability of solid lipid nanoparticles in dispersion. Acta Pharm 1998;48:257-67.

20. Lander R, Manger W, Scouloudis M, Ku A, Davis C, Lee A. Gaulin homogenization: a mechanistic study. Biotechnol Prog 2000;16:80-5.

21. Jahnke S. The theory of high pressure homogenization, in: Muller RH, Benita S, Bohm B. editors. Emulsions and nanosuspensions for the formulation of poorly soluble drugs. Stuttgart: Medpharm Scientific Publishers; 1998;177-200.

22. Mullen zur A, Feste Lipid-Nanopartikel mit prolongierter Wirkstoffliberation: Herstellung, Langzeitstabilitat, Charakterisierung, Freisetzungsverhalten und mechanismen. Ph.D. Thesis, Free University of Berlin;1996.

23. Eldem T, Speiser P, Hincal A. Optimization of spray-dried and congealed lipid microparticles and characterization of their surface morphology by scanning electron microscopy. Pharm Res 1991;8:47-54.

24. Speiser P. Lipidnanopellets als Tragersystem fur Arzneimittel zur peroralem Anwendung. European Patent No. EP 0167825;1990.

25. Sjostrom B, Bergenstahl B. Preparation of submicron drug particles in lecithin-stabilized $\mathrm{o} / \mathrm{w}$ emulsions. I. Model studies of the precipitation of cholesteryl acetate. Int J Pharm 1992;88:53-62.

26. Siekmann B, Westesen K. Investigations on solid lipid nanoparticles prepared by precipitation in $\mathrm{o} / \mathrm{w}$ emulsions. Eur J Pharm Biopharm 1996;43:104-9.

27. Gasco MR. Method for producing solid lipid microspheres having narrow size distribution. United State Patent. USS $188837 ; 1993$.

28. Gasco MR. Solid lipid nanospheres from warm microemulsions. Pharm Tech Eur 1997;9:52-8.

29. Boltri L, Canal T, Esposito PA, Carli F. Lipid nanoparticles: Evaluation of some critical formulation parameters. Proc Intern Symp Control Rel Bioact Mater 1993;20:346-7.

30. De Labouret A, Thioune O, Fessi H, Devissaguet JP, Puiseieux F. Application of an original process for obtaining colloidal dispersions of some coating polymers. Preparation, Charecterization, industrial scaling up. Drug Develop Ind Pharm 1995;21:229-41.

31. Cavalli R, Marengo E, Rodriguez L, Gasco MR. Effects of some experimental factors on the production process of solid lipid nanoparticles. Eur J Pharm Biopharm 1996;43:110-5.

32. Chen YJ, Jin RX, Zhou YQ, Zeng J, Zhang H, Feng QR. Preparation of solid lipid nanoparticles loaded with Xionggui powder-supercritical carbon dioxide fluid extraction and their evaluation in vitro release. Zhongguo Zhong Yao Za Zhi 2006;31:376-9.

33. Kaiser CS, Rompp H, Schmidt PC. Pharmaceutical applications of supercritical carbon dioxide. Pharmazie 2001;56:907-26.

34. Gosselin PM, Thibert R, Preda M, McMullen JN. Polymeric properties of micronized carbamazepine produced by RESS. Int J Pharm2003;252:225-33.

35. Freitas C, Mullera RH. Spray-drying of Solid lipid nanoparticles (SLN TM). Eur J Pharm Biopharm 1998;46:145-51.

36. Cortesi R, Esposito E, Luca G, Nastruzzi C. Production of lipospheres as carriers for bioactive compounds. Biomaterials 2002;23:2283-94.

37. Meyer E, Heinzelmann H. Scanning force microscopy. In: Wiesendanger R, Guntherodt HJ. Editors. Scanning tunneling microscopy II, Surface science. New York: Springer Verlag;1992:99-149.

38. Drake B, Prater CB, Weisenhorn AL, Gould SAC, Albrecht TR, Quate CF, et al. Imaging crystals polymers and process in water with the AFM. Science 1989;243:1586-9.

39. Jannin V, Musakhanian J, Marchaud D. Approach for the development of Solid and semi-solid lipid-based formulations. Adv Drug Deliv Rev2008;60:734-47.

40. Yang S, Zhu J, Lu Y, Ling B, Yang C. Body distribution of camptothecin solid lipid nanoparticles after oral administration. Pharm Res 1999;16:751-7.

41. Yang SC, Lu LF, Cai Y, Zhu JB, Liang BW, Yang CZ. Body distribution in mice of intravenously injected camptothecin solid lipid nanoparticles and targeting effect on brain. J Control Release 1999;59:299-307.

42. Zur Muhlen A, Mehnert W. Drug release and release mechanism of prednisolone loaded solid lipid nanoparticles. Pharmazie 1998;53:552-5.

43. Prow T, Smith JN, Grebe R, Salazar JH, Wang N, Kotov N, et al. Construction, gene delivery, and expression of DNA tethered nanoparticles. Mol Vis 2006;12:606-15.

44. Rudolph C, Schillinger U, Ortiz A, Tabatt K, Plank C, Muller $\mathrm{RH}$, et al. Application of novel Solid lipid nanoparticles (SLN)- gene vector formulations based on a diametric HIV1 VAT - peptide in vitro and in vivo. Pharmaceutic Res 2004;21(9):1662-9.

45. Hayes ME, Drummond DC, Kirpotin DB. Self-assembling nucleic acid-lipid nanoparticles suitable for targeted gene delivery. Gene Ther2006;13:646-51.

46. Pedersen N, Hansen S, Heydenreich AV, Kristensen HG, Poulsen HS. Solid lipid nanoparticles can effectively bind DNA, streptavidin and biotinylated ligands. Eur J Pharm Biopharm 2006;62:155-62.

47. Mei Z, Wu Q. Triptolide loaded solid lipid nanoparticle hydrogel for topical application. Drug Develop Ind Pharm 2005;31:161-8.

48. Chen H, Chang X, Du D, Liu W, Liu J. Weng T, et al. Podophyllotoxin-loaded solid lipid nanoparticles for epidermal targeting. J Control Release 2006;110:296-306.

49. Jenning V, Schafer-Korting M, Gohla S. Vitamin A-loaded solid lipid nanoparticles for topical use: drug release properties. J Control Release 2000;66:115-26.

50. Liu J, Hu W, Chen H, Ni Q, Xu H, Yang X. Isotretinoinloaded solid lipid nanoparticles with skin targeting for topical delivery. Int J Pharm2007;328:191-5.

51. Choi MJ, Kim JH, Maibach HI. Topical DNA vaccination with DNA/Lipid based complex. Curr Drug Deliv 2006;3:37-45.

52. Jain SK, Chourasia MK, Masuriha R. Solid lipid nanoparticles bearing flurbiprofen for transdermal delivery. Drug Deliv 2005;12:207-15.

53. Santos MC, Mehnert W, Schaller M. Drug targeting by solid lipid nanoparticles for dermal use. J Drug Target 2002;10:489-95.

54. Wissing SA, Muller RH. Solid lipid nanoparticles (SLN) a novel carrier for UV blockers. Pharmazie 2001;56:783-6.

55. Mei Z, Wu Q. Triptolide loaded solid lipid nanoparticle hydrogel for topical application. Drug Develop Ind Pharm 2005;31:161-8.

56. Wissing S, Lippacher A, Muller R. Investigations on the occlusive properties of solid lipid nanoparticles (SLN). J Cosmet Sci 2001;52:313-24. 
57. Jenning V, Gysler A, Schafer-Korting M, Gohla SH. Vitamin A loaded solid lipid nanoparticles for topical use: occlusive properties and drug targeting to the upper skin. Eur J Pharm Biopharm 2000;49:211-8.

58. Lai F, Wissing SA, Muller RH, Fadda AM. Artemisia arborescens L essential oil-loaded solid lipid nanoparticles for potential agriculture application: preparation and characterization. AAPS Pharm Sci Tech 2006;7(1):E2

59. Shenoy VS, Vijay IK, Murthy RS. Tumour targeting: biological factors and formulation advances in injectable lipid nanoparticles. J Pharm Pharmacol 2005;57:411-22.

60. Murthy RSR. Solid lipid nanoparticles as carriers for anticancer drugs to solid tumours. Drug Deliv 2005;12:385-92.

61. Ruckmani K, Sivakumar M, Ganeshkumar PA. Methotrexate loaded solid lipid nanoparticles (SLN) for effective treatment of carcinoma. J Nanosci Nanotechnol 2006;6:2991-5.

62. Yang SC, Lu LF, Cai Y, Zhu JB, Liang BW, Yang CZ. Body distribution in mice of intravenously injected camptothecin solid lipid nanoparticles and targeting effect on brain. J Control Release 1999;59:299-307.

63. Lu B, Xiong SB, Yang H., Yin XD, Chao RB. Solid lipid nanoparticles of mitoxantrone for local injection against breast cancer and its lymphnode metastases. Eur J Pharm Sci 2006;28:86-95.

64. Wong HL, Rauth AM, Bendayan R. A new polymer-lipid hybrid nanoparticle system increases cytotoxicity of doxorubicin against multidrug-resistant human breast cancer cells. Pharm Res 2006;23:1574-85.

65. Pandey R, Sharma S, Khuller GK. Oral SLN Based antitubercular chemotherapy. Tuberculosis (Edinb). 2005;85:415-20.

66. Dvorak HF, Wagy AJ, Dvorak JT, Dvorak AM. Stealth liposomes. J Pathol 1998;133:95-108.

67. Wang $\mathrm{Y}, \mathrm{Wu} \mathrm{W}$. In situ evading of phagocytic uptake of stealth solid lipid nanoparticles by mouse peritoneal macrophages. Drug Deliv 2006;13:189-92. 